\title{
Syringeal vocal folds do not have a voice in zebra finch vocal development
}

Alyssa Maxwell, Iris Adam, Pernille S. Larsen, Peter G. Sørensen, Coen P.H. Elemans* 5

Affiliation: Department of Biology, University of Southern Denmark, 5230 Odense,

Denmark

*Corresponding author: coen@biology.sdu.dk

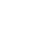

\section{Abstract}

Vocal behaviour can be dramatically changed by both neural circuit development and postnatal maturation of the body. During song learning in songbirds, both the song system and syringeal muscles are functionally changing, but it is unknown if maturation of sound generators within the syrinx contributes to vocal development. Here we densely sample the respiratory pressure control space of the zebra finch syrinx in vitro. We show that the syrinx produces sound very efficiently and that key acoustic parameters, minimal fundamental frequency, entropy and source level, do not change over development in both sexes. Thus, our data suggests that the observed acoustic changes in vocal development must be attributed to changes in the motor control pathway, from song system circuitry to muscle force, and not by material property changes in the avian analog of the vocal folds. We propose that in songbirds, muscle use and training driven by the sexually dimorphic song system are the crucial drivers that lead to sexual dimorphism of the syringeal skeleton and musculature. The size and properties of the instrument are thus not changing, while its player is.

Keywords: Vocal learning, neuromechanics, motor control, voice production 


\section{Introduction}

Many vertebrates change their vocal output over postnatal development ${ }^{1-4}$. Especially in species capable of vocal imitation learning, progressive changes in vocal output are attributed to changes in the underlying brain circuitry. However, the maturation of the vocal organ and tract have profound effect on voice during puberty in humans ${ }^{5}$, and can explain transitions from juvenile to adult calls in marmosets ${ }^{6}$. Thus, the postnatal development of the body can drive changes in vocal behavior, and therefore needs to be included when studying vocal development.

The zebra finch is a widespread animal model to study the mechanisms underlying vocal imitation learning and production ${ }^{7,8}$. In male zebra finches, sound production changes dramatically over the 100-day period of from hatching to adulthood ${ }^{2,9,10}$, developing from variable subsong to highly stereotyped crystallized song. These changes, including the ones in acoustic structure, are typically attributed to changes in neural circuitry, even though the vocal organ, the syrinx, is also undergoing significant anatomical and functional changes during this time ${ }^{11-14}$. Coinciding with the transition from the sensory to the sensorimotor phase of learning around $20 \mathrm{DPH}$, syringeal muscles in male zebra finches increase in mass and cross-sectional area $^{11}$. Additionally, the contractile properties of male syringeal muscles increase in speed ${ }^{12}$, which affects the transformation from neural commands to muscle force ${ }^{14}$. Thus, over development functional changes occur in the syrinx that change the transformation from neural signals into force which thereby change motor control of the vocal organ. However, it remains unknown if the organ itself also exhibits changes that will affect the complex transformation from muscle forces to sound.

Analogous to mammals, birds produce sound when expiratory airflow from the bronchi induces self-sustained vibrations of vocal fold-like structures within the syrinx ${ }^{15-18}$ (Fig. 1a) following the myoelastic-aerodynamic (MEAD) theory for voice production ${ }^{19}$. Songbirds have two bilateral sets of independently controlled paired folds or labia, one in each bronchus or hemi-syrinx, with the lateral labium on the lateral side, and medial vibratory mass (MVM) on the medial side. The MVM is a tissue continuum in which the thicker part is called the medial labium (ML) $)^{20-22}$ (Fig. 1b). These labia consist of multiple layers of tissue in most species investigated $^{22,23}$. According to MEAD, acoustic features, such as fundamental frequency $\left(f_{\mathrm{o}}\right)$, or boundary conditions for vibration, such as the phonation threshold pressure, are largely set by the positioning of and driving pressures ${ }^{19}$ on the vocal folds, as well as their resonance properties and shape. Vocal fold resonance properties in turn are determined by vocal fold length and ultrastructure, such as collagen and elastin fiber composition, the occurrence of 
61 tissue layering and layer orientation ${ }^{24}$. During vocal development in humans ${ }^{25-27}$, and marmosets ${ }^{6}$, changes in size, (ultra)structure and mechanical properties of the labia have been linked to dramatic changes in vocal output. However, it is unknown whether material properties or morphology of songbird labial change over vocal development and if so whether these changes contribute to the changing vocal output.

Tension and positioning of labia are modulated directly by two independent motor systems in songbirds: the respiratory and the syringeal motor system. The respiratory system generates the pressure and flow driving vibration of the avian vocal folds. In zebra finches, a sound pulse is produced when these tissues collide within the vibratory cycle ${ }^{15}$. Additionally, the syrinx is suspended in a pressurized air sac, the interclavicular air sac (ICAS), that is essential for sound production in birds ${ }^{15,28,29}$. The pressure differential between bronchial pressure $\left(p_{\mathrm{b}}\right)$ and ICAS pressure ( $\left.p_{\text {icas }}\right)$ results in a net pressure, the transmural pressure $\left(p_{\mathrm{t}}\right)$, that applies a net force on the MVM. This force has been shown to correlate most closely to changes in $f_{\mathrm{o}}$ during manipulation of $p_{\text {icas }}$ in $v i v o^{29}$ and ex vivo ${ }^{15}$, but we do not know how these pressures interact to drive acoustic parameters.

The syringeal motor system of songbirds consists of up to 8 pairs of intrinsic and extrinsic syringeal muscles ${ }^{21,30,31}$ (Fig. 1a), which control the positioning of individual bones within the syringeal skeleton as well as the torque on them. Consequently, syrinx muscles thereby - either directly or indirectly - modulate the adduction level and tension of the labia, which are suspended between the bones ${ }^{32}$. The control space of syringeal muscles is vast due to its multidimensionality and only limitedly understood ${ }^{15,31,33}$. Taken together, both, changes in the motor control spaces or the sound production properties of the syrinx within this space could contribute to vocal development, but this is currently unknown.

Here we test if the acoustic output of the zebra finch syrinx sound generators changes over vocal development. We focused on the syringeal dynamics controlled by respiratory pressures and densely sampled the control space of bronchial versus air sac pressure. 
Materials and Methods

\section{$\underline{\text { In vitro sound production }}$}

Animals use and care

Zebra finches (Taeniopygia guttata, order Passeriformes) were kept and bred in group aviaries at the University of Southern Denmark, Odense, Denmark on a 12:12 hour light:dark photoperiod and given water and food ad libitum. All experiments were conducted in accordance with the Danish law concerning animal experiments and protocols were approved by the Danish Animal Experiments Inspectorate (Copenhagen, Denmark). Adult birds were provided with nesting material, ad libitum. Nest boxes were monitored daily, so that birds could be accurately aged. Breeding began in December 2017 and ended November 2018.

We studied vocal output of the syrinx in vitro in four age groups: $25 \mathrm{DPH}(\mathrm{N}=5$ males, $\mathrm{N}=5$ females), $50 \mathrm{DPH}(\mathrm{N}=4$ males, $\mathrm{N}=4$ females $), 75 \mathrm{DPH}(\mathrm{N}=6$ males, $\mathrm{N}=4$ females $)$, and $100 \mathrm{DPH}(\mathrm{N}=5$ males, $\mathrm{N}=6$ females). Sex was determined by dissection postmortem ( 25 $\mathrm{DPH}$ ) or plumage (all other ages).

Syrinx mounting procedure

Animals were euthanized by Isoflurane (Baxter, Lillerød, Denmark) overdose. The syrinxes were dissected out while being regularly flushed and then submerged in a bath of oxygenated Ringer's solution (recipe $\mathrm{cf} .{ }^{34}$ ) on ice. Each syrinx was photographed with a Leica DC425 camera mounted on a stereomicroscope (M165-FC, Leica Microsystems, Switzerland) prior to being placed inside the experimental chamber. Each bronchus was placed over polyethylene tubing (outer diameter $0.97 \mathrm{~mm}$ x inner diameter $0.58 \mathrm{~mm}$, Instech Salomon, PA, USA) and secured with 10-0 nylon suture (AROSurgical, Newport Beach, CA, USA). The trachea was placed into a $1 \mathrm{~mL}$ pipette which was cut to the length of $15 \mathrm{~mm}$ (outer diameter

$1132.4 \mathrm{~mm}$, inner diameter $1.4 \mathrm{~mm}$ ). Some adipose tissue was left on the trachea to ensure an airtight connection. To control the pressure inside the chamber it was made airtight with a glass lid, which also allowed visualization of the syrinx through the stereomicroscope.

Experimental setup

118 We designed an experimental setup that allows studying the mechanical behavior of the 119 syrinx in vitro or ex vivo (described in detail in $\left.{ }^{15}\right)$. The bronchial pressure $\left(p_{\mathrm{b}}\right)$ and pressure in 120 the experimental chamber (i.e. interclavicular air sac pressure, $p_{\text {icas}}$ ) can be controlled 121 independently by two dual-valve differential pressure PID controllers (model PCD, 0-10 kPa, 
122 Alicat Scientific, AZ, USA). Bronchial flow through the syrinx was measured with a MEMS

123 flow sensor (PMF2102V, Posifa Microsystems, San Jose, USA) about $7 \mathrm{~cm}$ upstream from the

124 bronchial connection. Sound was recorded with a $1 / 2$ inch pressure microphone-pre-amplifier

125 assembly (model 46AD, G.R.A.S, Denmark), amplified and high-pass filtered (0.2 Hz, 3-pole

126 Butterworth filter, model 12AQ, G.R.A.S., Denmark). The sound recording sensitivity was

127 tested before each experiment using a $1 \mathrm{kHz}$ tone (sound calibrator model 42AB, G.R.A.S.,

128 Denmark). The microphone was placed $15 \mathrm{~cm}$ from the tracheal connector outlet and 129 positioned at a $45^{\circ}$ angle to avoid the air jet from the tracheal outlet. The sound, pressure and

130 flow signals were low-pass filtered at $10 \mathrm{kHz}$ (model EF120, Thor Labs) and digitized at 50

$131 \mathrm{kHz}$ (USB 6259, 16 bit, National Instruments, Austin, Texas).

132

Experimental protocol

134 To explore the acoustic output of the avian syrinx (Fig. 1a), we subjected the syrinxes to $135 p_{\mathrm{b}}$ ramps from $0-3 \mathrm{kPa}$ (over atmospheric pressure) at $1 \mathrm{kPa} / \mathrm{s}$ with $p_{\text {icas }}$ at a constant pressure. 136 In one run, we applied $13 p_{\text {icas }}$ settings at equidistant $0.23 \mathrm{kPa}$ intervals between 0 and $3 \mathrm{kPa}$ in 137 a randomized order with $2 \mathrm{~s}$ pause $\left(p_{\mathrm{b}}\right.$ and $p_{\text {icas }}=0 \mathrm{kPa}$ ) between ramps (Fig. 1c). We avoided 138 high flow regimes $\left(p_{\mathrm{t}}>2 \mathrm{kPa}\right)$ to decrease desiccation and avoid potential damage to the syrinx.

139 When water in the bronchi or trachea prevented normal sound production in part of the run, we 140 repeated the entire run. We subjected left and right hemi-syrinx separately in randomized order 141 to this paradigm by allowing air flow only through one side and kept a one-minute rest between 142 runs. The total duration for the experiment was maximally 20 minutes per individual.

\section{Data Analysis}

Sound was filtered with a $0.1 \mathrm{kHz} 3^{\text {rd }}$ order Butterworth high-pass filter, pressure and

146 flow signals were filtered with a $2 \mathrm{kHz} 3^{\text {rd }}$ order Butterworth low-pass filter, all with zero147 phase shift implementation (filtfilt function, Matlab). Sound, pressure and flow signals were 148 binned in $2 \mathrm{~ms}$ duration bins, with a sliding window of $1 \mathrm{~ms}$, and we calculated several 149 parameters per bin. We calculated the RMS values for all signals. For the sound signal, we 150 additionally extracted the fundamental frequency $\left(f_{\mathrm{o}}\right)$, source level (SL) and Wiener entropy 151 (WE).

152 Fundamental frequency was extracted using the yin-algorithm ${ }^{35}$ by manually optimizing 153 minimal aperiodicity $(0.05-0.2)$ and power $(0.25-5.0 \mathrm{mPa})$. Source level at $1 \mathrm{~m}$ distance 154 (SL) of the emitted sound was defined as: 


$$
\mathrm{SL}=20 \log _{10} \frac{P}{P \mathrm{o}}+20 \log _{10} \mathrm{r}
$$

where $p$ is the RMS of sound pressure $(\mathrm{Pa}), p_{\mathrm{o}}$ is the reference pressure in air of $20 \mu \mathrm{Pa}$, and $\mathrm{r}$ the distance $(\mathrm{m})$ from the tracheal outlet to the microphone. To calculate WE, we first computed the amplitude spectrum Px of each bin using the periodogram method $(\mathrm{nfft}=2048$, overlap $=1024$ samples). WE was defined as:

$$
W E=\log _{10}\left(\frac{\text { geomean }(P x)}{\operatorname{mean}(P x)}\right) \text {. }
$$
pressures (PTP) were identified for $p_{\text {icas, }} p_{\mathrm{b}}$, and $p_{\mathrm{t}}$ as the first pressure value for each $p_{\mathrm{b}}$ ramp where sound power crossed the set threshold. The minimal $f_{\mathrm{o}}$ was defined as the average $f_{\mathrm{o}}$ of the first value for each $p_{b}$ ramp where sound power crossed the set threshold. Minimal SL was defined as the lowest SL value of all $p_{b}$ ramps per side.

By combining pressure, flow and sound signals we were able to calculate the mechanical efficiency $(\mathrm{ME})$ as the ratio (in $\mathrm{dB})$ of acoustical power $\left(P_{\text {acoustic }}\right)$ over aerodynamic power ( $\left.P_{\text {aerodynamic }}\right)$ :

$$
\mathrm{ME}=10 \log 10\left(\frac{P_{\text {acoustic }}}{P_{\text {aerodynamic }}}\right),
$$

The acoustic power (W) was assumed to radiate over half a sphere: $P_{\text {acoustic }}=\frac{4 \pi r^{2} p^{2}}{\rho v}$, with air density $\rho=1.2 \mathrm{~kg} \mathrm{~m}^{-3}$, speed of sound $v=344 \mathrm{~m} \mathrm{~s}^{-1}$, and $p$ the RMS sound pressure in Pa. The aerodynamic power $P_{\text {aerodynamic }}=p_{\mathrm{b}} V$ where $p_{b}$ is the bronchial pressure $(\mathrm{Pa})$ and $V$ is the flow rate $\left(\mathrm{m}^{3} \mathrm{~s}^{-1}\right.$.) All data analysis was done in Matlab ${ }^{36}$ and $\mathrm{R}$ version 3.5.1 ${ }^{37}$.

\section{MVM dimensions}

After the experimental protocol, each syrinx was pinned down in the situ position and kept in $4 \%(\mathrm{w} / \mathrm{v})$ paraformaldehyde for 24 hours at $4{ }^{\circ} \mathrm{C}$. It was then placed in PBS and stored at $4^{\circ} \mathrm{C}$. To quantify the projected size of the MVM of each hemi-syrinx, we carefully cut the syrinx in half and made pictures of the medial side of the medial tympaniform membranes

180 (MTMs) (Fig. 8d,e), and the lateral view of each hemi-syrinx using a Leica DC425 camera mounted on a stereomicroscope (M165-FC, Leica Microsystems, Switzerland) in Leica Application Suite (LAS Ver. 4.7.0). We measured the distances between physiological landmarks in the MTM following ${ }^{20,32}$ : (i) the distance between the medio-ventral cartilage

184 (MVC) and the lateral dorsal cartilage (LDC), and (ii) the distance between the LDC and the medio-dorsal cartilage (MDC). Distance measurements between cartilages were taken edgeto-edge in the middle of the cartilage. Additionally, we measured the area of the LDC which is 
fully suspended in the MVM. Length and area measurements were taken using ImageJ (Ver. $\left.2.0 .0-\mathrm{rc}-69 / 1.52 \mathrm{p} ;{ }^{38}\right)$.

\section{$\underline{\text { In vivo sound production }}$}

191 To measure the lowest fundamental frequency produced by an unactuated syrinx in vivo, 192 we performed unilateral tracheosyringeal nerve lesions on the right side of the syrinx of 193 juvenile and adult males.

Sound recordings

Song was recorded in custom-built, sound attenuated recording boxes $(60 \times 95 \times 57 \mathrm{~cm})$ and vocalizations were recorded continuously using a omnidirectional microphone (Behringer ECM8000) mounted $12 \mathrm{~cm}$ above the cage connected to an amplitude triggered recording software (Sound Analysis Pro; ${ }^{39}$ ). Sound was digitized at a sampling rate of $44.1 \mathrm{kHz}$ with $16-$ bit resolution (Roland octa capture, amplification $40 \mathrm{~dB}$ ). Adult birds were recorded right before and 3 weeks after denervation. Juveniles were recorded at 50 and $100 \mathrm{DPH}$.

Tracheosyringeal nerve lesions

Unilateral denervations of the tracheosyringeal nerve were performed as previously described $^{40}$. In brief, birds were anesthetized with isoflurane (induction $3 \%$, maintenance 1.5 $2 \%$ ) and a $5 \mathrm{~mm}$ section of the right tracheosyringeal nerve was removed from the trachea through a small incision of the skin. After that the skin was re-sutured and the birds were allowed to recover in a heated cage. Adults were subsequently transferred to holding cages. Juveniles received surgery at $30 \mathrm{DPH}$ and were returned to their parents after surgery.

Adult birds: For each bird ( $\mathrm{N}=5$, age $>120 \mathrm{DPH}$, days post-surgery: $20 \pm 2$ ), the most common motif was determined by two experienced observers (IA, CPHE) in recordings acquired before denervation. Subsequently, the same motif was identified in recordings acquired 3 weeks after denervation. A custom written GUI (Matlab) was used to extract motifs from post denervation sound recordings. 200 motifs per bird were randomly selected for analysis. WAV files were high pass filtered at $0.3 \mathrm{kHz}$ using a $3^{\text {rd }}$ order Butterworth filter. Syllables were assigned to be produced by the left or right hemi-syrinx based on whether their spectral content stayed the same or changed after denervation, respectively following earlier results by ${ }^{41,42}$. 
Juvenile birds: Song of juvenile males $(\mathrm{N}=6)$ was analyzed on recordings from $50 \mathrm{DPH}$ (DPH $52.8 \pm 1$, days post-surgery: $22.3 \pm 0.8$ ). At this age, the syllable structure is not fully stereotyped, but motifs usually can be distinguished. We thus measured the lowest fundamental frequency of 50 motifs per bird irrespective of syllable identity. As the juvenile birds were denervated while singing subsong, we couldn't distinguish which syllable was produced on which side. Under the assumption that the lowest fundamental is produced by the denervated side, we classified the measured syllables as right produced.

In all birds, frequencies were measured on spectrograms of post denervation recordings (FFT size: 1024, overlap: 75\%, Hanning window) in SASlab (Avisoft, Germany). In all juvenile birds the frequency of the lowest harmonic (i.e $f_{\mathrm{o}}$ ) was measured. In all other cases, to increase the $f_{\mathrm{o}}$ resolution, we measured the $3-5$ th harmonic and $f_{\mathrm{o}}$ was calculated as:

$$
f_{\mathrm{o}}=f_{n} / n \text {. }
$$

where $n$ is the $\mathrm{n}^{\text {th }}$ harmonic. If several different syllables where analyzed for the adult birds the syllable with the lowest mean fundamental frequency (per side) was selected for

\section{$\underline{\text { Statistics }}$} statistical analysis.

To asses which pressure $\left(p_{\mathrm{b}}, p_{\text {icas }}, p_{\mathrm{t}}\right)$ drives $f_{\mathrm{o}}$ and SL in adults, we used a delta Bayesian information criterion $(\triangle \mathrm{BIC})$ approach. In a first step, we fit a linear model to the $f_{\mathrm{o}}$-pressure and SL-pressure relationship. We then computed the BIC values for these models and subtracted the BIC of the null model with no pressure variable $\left(f_{\mathrm{o}}=1 ; \mathrm{SL}=1\right)$ to calculate the $\triangle \mathrm{BIC}$ score. The model with the lowest $\triangle \mathrm{BIC}$ score represents the model with the best fit.

To compare the $f_{\mathrm{o}}-p_{\mathrm{t}}$ and $\mathrm{SL}-p_{\mathrm{b}}$ relationship over ages and between side and sex, we fit individual linear models to the data and extracted the slopes. For $f_{\mathrm{o}}$ we split the data in two regions: region $\mathrm{S} 1\left(p_{\mathrm{t}}=0-0.75 \mathrm{kPa}\right)$ and region $\mathrm{S} 2\left(p_{\mathrm{t}}=0.75-2 \mathrm{kPa}\right)$.

To test whether age, sex or side of the syrinx had a significant effect on our response variables, we fit linear mixed effect models (LMMs) to our data using the lmer function of the lmerTest package ${ }^{43}$ with maximum likelihood optimization. Sex, side and age were fit as fixed effects and animal was included as a random effect to correct for dependence. Model equations can be found in Table S1, S2 and S3. To determine which effects significantly contribute to the model, we performed model selection using a Likelihood Ratio Test (LRT) with the Chi squared distribution using the lme4 package ${ }^{44}$. The difference between the absolute difference in minimal $f_{\mathrm{o}}$ between sexes and the difference in minimal $f_{\mathrm{o}}$ in vivo was assessed with Welch's 
254 t-test. The difference between $\mathrm{S} 1$ and $\mathrm{S} 2$ slopes for $f_{\mathrm{o}}$ were assessed using paired t-tests for 255 males and females.

256 All reported values in the text are mean \pm SD. All error bars in figures are S.D. The 257 outputs of al LMMs are reported in Supplementary Table S1, S2, and S3. We chose to present 258 data in figures spilt by sex even when not significant. Statistical significance was accepted at $259 \mathrm{p}<0.05$ for all statistical tests. 


\section{Results}

We developed an experimental paradigm to quantify sound production as a function of driving parameters, because predicting the behavior of this complicated nonlinear system from anatomy or isolated mechanical property tests alone will only present correlates or rough estimates. Because we still have limited knowledge on the biomechanical effect of all syringeal muscles, we focused on syringeal dynamics controlled by respiratory pressures.

Acoustic output of the adult syrinx

To quantify the functional acoustic output of the adult male and female zebra finch syrinx, we densely sampled the bronchial $\left(p_{\mathrm{b}}\right)$ and interclavicular $\left(p_{\text {icas }}\right)$ pressure control space in isolated left and right hemi-syrinxes in vitro. For all zebra finch syrinxes tested, sound was produced in a pressure space enclosed by a minimal $p_{\mathrm{b}}$ and $p_{\text {icas }}$ and exclusively in the lower half of the $p_{\mathrm{b}}, p_{\text {icas }}$ space (Fig. 1d). Here a differential or transmural pressure $\left(p_{\mathrm{t}}\right)$ exerts force on the MVM that is positive when directed outwards from bronchus to surrounding air sac. We quantified the phonation threshold pressures (PTP) for the three pressures (Fig. 1g). The $\mathrm{PTP}_{\mathrm{b}}$ was not significantly different for $\operatorname{sex}(\mathrm{LMM}, p=0.418)$ or side (LMM, $p=0.395)$ and was $1.01 \pm 0.28 \mathrm{kPa}$ (range: $0.64-1.68 \mathrm{kPa}, \mathrm{N}=11$ ). The $\mathrm{PTP}_{\text {icas }}$ was also not significant different for $\operatorname{sex}(\mathrm{LMM}, p=0.638)$ or side $(\mathrm{LMM}, p=0.223)$ and was $0.45 \pm 0.27 \mathrm{kPa}$ (range: $0.22-$ $1.07 \mathrm{kPa}, \mathrm{N}=11)$. The $\mathrm{PTP}_{\mathrm{t}}$ was also not significantly different for sexes (LMM, $p=0.057$ ) or side (LMM, $p=0.395)$ and was $0.15 \pm 0.19 \mathrm{kPa}($ range: $4 \mathrm{e}-5-0.75 \mathrm{kPa}, \mathrm{N}=11)$.

Next, we quantified the acoustic output of the adult zebra finch hemi-syrinx within the $p_{\mathrm{b}}-p_{\text {icas }}$ control space for three parameters: fundamental frequency $\left(f_{\mathrm{o}}\right)$, source level (SL) and Wiener entropy (WE). In all animals, fundamental frequency was gradually modulated depending on different combinations of $p_{\mathrm{b}}$ and $p_{\text {icas }}$ (Fig. 1d-f). Frequency jumps were not observed. Of all pressures, $p_{\mathrm{t}}$ described the $f_{\mathrm{o}}$ data best ( $\triangle \mathrm{BIC}=-528$, see Methods). The continuous, smooth increase of $f_{\mathrm{o}}$ with $p_{\mathrm{t}}$ can be clearly seen in Fig. 1e,f. In males, the right typically produced higher frequencies than the left as a function of $p_{\mathrm{t}}$ (Fig. 1e). However, the minimal $f_{\mathrm{o}}$ produced was not significantly different and was $511 \pm 102 \mathrm{~Hz}$ (range: $352-613$ $\mathrm{Hz}, \mathrm{N}=5$ ) and $513 \pm 123 \mathrm{~Hz}$ (range: $312-625 \mathrm{~Hz}, \mathrm{~N}=5$ ) for left and right hemi-syrinx respectively (Fig. 1h). To describe $f_{\mathrm{o}}$ as a function of $p_{\mathrm{t}}$, we split the data in to two regions (Fig. $1 \mathrm{e}, \mathrm{f})$; region $\mathrm{S} 1\left(p_{\mathrm{t}}=0-0.75 \mathrm{kPa}\right)$ and region $\mathrm{S} 2\left(p_{\mathrm{t}}=0.75-2 \mathrm{kPa}\right)$ and fit linear models to the data. The slope of S1 was $189 \pm 76 \mathrm{~Hz} / \mathrm{kPa}$ (range: $67-453 \mathrm{~Hz} / \mathrm{kPa}, \mathrm{N}=5$ ), and was significantly higher than the S2 slope of $55 \pm 58 \mathrm{~Hz} / \mathrm{kPa}$ (range: $25-310 \mathrm{~Hz} / \mathrm{kPa}, \mathrm{N}=5$ ) by $134 \pm 18 \mathrm{~Hz} / \mathrm{kPa}$ (Fig. 1j) (paired t-test, $\mathrm{t}=5.3061, \mathrm{df}=9, p=5 \mathrm{e}-4$ ). In females, the minimal 
$f_{\mathrm{o}}$ produced was $529 \pm 84 \mathrm{~Hz}$ (range: $435-678 \mathrm{~Hz}, \mathrm{~N}=6$ ) for the left and $568 \pm 57 \mathrm{~Hz}$ (range: $518-650 \mathrm{~Hz}, \mathrm{~N}=6$ ) for the right hemi-syrinx (Fig. 1f). The slope of the $\mathrm{S} 1$ region was $181 \pm$ $108 \mathrm{~Hz} / \mathrm{kPa}$ (range: $67-453 \mathrm{~Hz} / \mathrm{kPa}, \mathrm{N}=6$ ) and was also significantly higher than the $\mathrm{S} 2$ slope of $55 \pm 58 \mathrm{~Hz} / \mathrm{Pa}$ (range: $-42-167 \mathrm{~Hz} / \mathrm{kPa}, \mathrm{N}=6$ ) by $126 \pm 51 \mathrm{~Hz} / \mathrm{kPa}$ (Fig. 1j) (paired t-test, $\mathrm{t}=3.31, \mathrm{df}=10, p=0.0079)$. Comparing the sexes, the difference in minimal $f_{\mathrm{o}}$ between left and right seemed smaller in males than in females (Fig. 1i), but this effect was not significant (Welch's t-test, $\mathrm{t}=-1.08, \mathrm{df}=6.42, \mathrm{p}=0.32$ ). The slopes of both $\mathrm{S} 1$ and $\mathrm{S} 2$ were not significant different between sex and side and were $185 \pm 92 \mathrm{~Hz} / \mathrm{kPa}$ (range: $25-453 \mathrm{~Hz} / \mathrm{kPa}, \mathrm{N}=11$ ) and $55 \pm 58 \mathrm{~Hz} / \mathrm{kPa}$ (range: $-42-167, \mathrm{~N}=11$ ), for $\mathrm{S} 1$ and $\mathrm{S} 2$, respectively (Fig. $1 \mathrm{j}$, Supplementary Table S1).

Source level at $1 \mathrm{~m}$ distance was best described by $p_{\mathrm{b}}(\triangle \mathrm{BIC}=-78,996)$ and increased linearly with pressure in both sexes (Fig. 2a-c). The minimum SL (Fig. 2d) was not significantly different for sex (LMM, $p=0.149)$ or side $(\mathrm{LMM}, p=0.225)$ and was $45 \pm 4 \mathrm{~dB}$ re $20 \mu \mathrm{Pa} @$ $1 \mathrm{~m}$ (range: 37 - $51 \mathrm{~dB}$ re $20 \mu \mathrm{Pa} @ 1 \mathrm{~m}, \mathrm{~N}=11$ ). The slope of the SL- $p_{\mathrm{b}}$ relationship (Fig. 2e) did not differ significantly between males and females (LMM, $p=0.704)$, but was significantly higher on the right side $(5 \pm 2 \mathrm{~dB} / \mathrm{kPa}, \mathrm{N}=11)$ than the left side $(4 \pm 1 \mathrm{~dB} / \mathrm{kPa}, \mathrm{N}=11)(\mathrm{LMM}$, $p=0.016$ ).

WE did not show any obvious relation to $p_{\mathrm{b},} p_{\text {icas, }}$ or $p_{\mathrm{t}}$, and therefore we considered the mean of the entire control space (Fig. 3a). The mean WE did not differ significantly between sexes (LMM, $p=0.138)$ or sides $(\mathrm{LMM}, p=0.661)$ and was $-1.8 \pm 0.12 \mathrm{~dB}$ (range: -1.6 to -2.1 $\mathrm{dB}, \mathrm{N}=11)$ (Fig. 3b).

Our setup allowed us to calculate the mechanical efficiency (ME) of sound production, which estimates how much of the power in the air flow is transformed into sound (see Methods, Fig. 4). We found that ME did not vary systematically with $p_{\mathrm{b}}, p_{\text {icas, }}$ or $p_{\mathrm{t}}$ and therefore considered the mean of the entire control space (Fig. 4b). ME was not significantly different between sexes (LMM, $p=0.118$ ), but was significantly lower (LMM, $p=0.027$ ) on the right side $(-36 \pm 1.8 \mathrm{~dB}$, range: -39 to $-33, \mathrm{~N}=10)$ compared to the left $(-35 \pm 2.2 \mathrm{~dB}$, range; -38 to $-31 \mathrm{~dB}, \mathrm{~N}=10)$ (Fig. 4c).

\section{Acoustic control space does not change over vocal development}

Next, we tested if the output of the isolated zebra finch syrinx changed over vocal development from 25 to $100 \mathrm{DPH}$ (Fig. 5). Like in the adult syrinx, sound was produced exclusively in the lower half of the syringeal $p_{\mathrm{b}}, p_{\text {icas }}$ space over vocal development. The $\mathrm{PTP}_{\mathrm{b}}$ was not significantly affected by age (LMM, $p=0.257)$, side (LMM, $p=0.268)$, or sex (LMM, 
$p=0.558$ ) and was $0.9 \pm 0.24 \mathrm{kPa}$ (range: $0.53-1.68 \mathrm{kPa}, \mathrm{N}=32)$. $\mathrm{PTP}_{\text {icas }}$ demonstrated a small but significant increase with age $(\mathrm{LMM}, p=0.002)$, but no significant difference between sexes $(\mathrm{LMM}, p=0.762)$ or sides (LMM, $p=0.274)$, and went from $0.21 \pm 0.8 \mathrm{kPa}$ at $25 \mathrm{DPH}$ (range: $0.006-0.25 \mathrm{kPa}, \mathrm{N}=8$ ) to $0.37 \pm 0.25 \mathrm{kPa}$ at $100 \mathrm{DPH}$ (range: $0.21-1.1 \mathrm{kPa}, \mathrm{N}=$ 11).

Consistently, $\mathrm{PTP}_{\mathrm{t}}$ also demonstrated a small but significant decrease with age from 0.17 $\pm 0.08 \mathrm{kPa}$ at $25 \mathrm{DPH}$ (range: $0.06-0.31 \mathrm{kPa}, \mathrm{N}=8$ ) to $0.03 \pm 0.06 \mathrm{kPa}$ at $100 \mathrm{DPH}$ (range: 4e-5- $0.16 \mathrm{kPa}, \mathrm{N}=11)$, and marginally, but significantly lower in males $(0.0846 \pm 0.0981$ $\mathrm{kPa})$ compared to females $(0.1047 \pm 0.0875)$.

We examined changes in the syringeal $p_{\mathrm{b}}-p_{\text {icas }}$ control space for three acoustic parameters: fundamental frequency $\left(f_{\mathrm{o}}\right)$, source level (SL) and Wiener entropy (WE). Over development, $f_{\mathrm{o}}$ was also gradually modulated within the $p_{\mathrm{b}-p_{\text {icas }}}$ space and did not exhibit frequency jumps (Fig. 5). In males and females, the minimal $f_{\mathrm{o}}$ produced by each hemi-syrinx in vitro did not change significantly from $25 \mathrm{DPH}$ to $100 \mathrm{DPH}$ (Fig. 5b), but the left hemisyrinx produced a significantly lower minimal $f_{\mathrm{o}}$ than the right (males: L: $487 \pm 106 \mathrm{~Hz}, \mathrm{~N}=$ 18, R: $519 \pm 104 \mathrm{~Hz}, \mathrm{~N}=18$, females: L: $480 \pm 83 \mathrm{~Hz}, \mathrm{~N}=15$, R: $590 \pm 69 \mathrm{~Hz} \mathrm{~N}=15)$ (LMM, $p<0.001)$. Interestingly, in 5 out of 18 males the left-right difference was reversed.

The slope of the $f_{\mathrm{o}}-p_{\mathrm{t}}$ relationship in region $\mathrm{S} 1$ did not significantly change with age $(\mathrm{LMM}, p=0.651)$, sex (LMM, $p=0.630)$, or side $(\mathrm{LMM}, p=0.270)$ and was $91 \pm 109 \mathrm{~Hz} / \mathrm{kPa}$ (range: $-204-250 \mathrm{~Hz} / \mathrm{kPa}, \mathrm{N}=32$ ). The slope in region $\mathrm{S} 2$ was significantly different between ages (LMM, $p=0.0273)$, but not for sex (LMM, $p=0.464)$, or side (LMM, $p=0.474)$, and was $88 \pm 43 \mathrm{~Hz} / \mathrm{kPa}$ (range: $31-146 \mathrm{~Hz} / \mathrm{kPa}, \mathrm{N}=8$ ), $62 \pm 28 \mathrm{~Hz} / \mathrm{kPa}$ (range: $18-105 \mathrm{~Hz} / \mathrm{kPa}$, $\mathrm{N}=7$ ), $70 \pm 46 \mathrm{~Hz} / \mathrm{kPa}$ (range: $5-149 \mathrm{~Hz} / \mathrm{kPa}, \mathrm{N}=7$ ), and $65 \pm 50 \mathrm{~Hz} / \mathrm{kPa}$ (range: -43 - 135, $\mathrm{N}=11$ ) for $25,50,75$, and $100 \mathrm{DPH}$ respectively.

Source level increased with $p_{\mathrm{b}}$ for all animals (Fig. 6a,e), but the minimal source level did not change significantly with age (LMM, $p=0.680)$, sex (LMM, $p=0.374)$, or side (LMM, $p=0.271)$ and was $44 \pm 4 \mathrm{~dB}$ re20 $\mu \mathrm{Pa} @ 1 \mathrm{~m}$ (range: $36-51 \mathrm{~dB}, \mathrm{~N}=32)$ (Fig. 6b-c). The SL$p_{\mathrm{b}}$ slope also did not change with age (LMM, $\left.p=0.83\right)$, or sex (LMM, $\left.p=0.874\right)$, but was significantly less steep (LMM, $p=0.037)$ on the left $(4.1 \pm 1.0 \mathrm{~dB} / \mathrm{kPa}$, range: $1.9-6.2 \mathrm{~dB} / \mathrm{kPa}$, $\mathrm{N}=32)$ versus right hemi-syrinx $(4.7 \pm 1.6 \mathrm{~dB} / \mathrm{kPa}$, range: $0.9-7.4 \mathrm{~dB} / \mathrm{kPa}, \mathrm{N}=32)$ by $0.6 \pm$ $0.3 \mathrm{~dB}(\mathrm{~N}=32)$.(Fig. $6 \mathrm{~d})$. Mean WE did not change significantly for any of the parameters tested (LMM, age: $p=0.070$, sex: $p=0.979$, side: $p=0.084$ ), and was $-1.8 \pm 0.1 \mathrm{~dB}$ (range: 2.1 to $-1.6 \mathrm{~dB}, \mathrm{~N}=32$; Fig. 7a-b, e-f). 
Next, we calculated the mechanical efficiency (ME) to test if the ability of the syrinx to convert mechanical power to sound changed over song development (Fig. 7c,g). ME did not significantly change with $\operatorname{sex}(\mathrm{LMM}, p=0.091)$ or side $(\mathrm{LMM}, p=0.101)$, but demonstrated a small but significant decrease (LMM, $p=0.046$ ) from $-33 \pm 1.7 \mathrm{~dB}$ (range: -37 to $-31 \mathrm{~dB}, \mathrm{~N}$ $=8$ ) at $25 \mathrm{DPH}$ to $-35 \pm 1.8 \mathrm{~dB}$ (range: -39 to $-33 \mathrm{~dB}, \mathrm{~N}=10$ ) in adults (Fig. $7 \mathrm{~d}, \mathrm{~h}$ ).

Taken together, we observed that the acoustic output of the syrinx control space did not

368

369

370

371

372

373

374

375

376

377

378

379

380

381

382

383

384

385

386

387

388

389

390

391

392

393

394

\section{Morphological changes over development}

We lastly investigated if the medial vibratory mass (MVM) dimensions change over development. We focused on non-invasive photographic techniques because detailed histological or material property testing was beyond the scope of the present study. The tension in the MVM can be increased by the shortening of two syringeal muscles that insert on the medio-ventral cartilage (MVC) and medio-dorsal cartilage (MDC) ${ }^{21}$ (Fig. 8a-c). A third cartilage, the lateral dorsal cartilage (LDC), is embedded within the MVM. A thickening of the tissue between the MVC and LDC is called the medial labium. The two syringeal muscles change the tension of the MVM by changing the distance between 1) MVC and LDC and 2) LDC and MDC (Fig. 8b,c). The MVC - LDC length did not change with sex (LMM, $p=0.72)$ or age (LMM, $p=0.446)$, but was significantly (LMM, $p=0.002)$ longer on the left $(1.13 \pm$ $0.10 \mathrm{~mm}$; range: $965-1297 \mu \mathrm{m}, \mathrm{N}=29)$ compared to the right $(1.05 \pm 0.11 \mathrm{~mm}$, range: $798-$ $1363 \mu \mathrm{m}, \mathrm{N}=29$ ) (Fig. 8f). The LDC - MDC length also did not change with sex (LMM, $p=$ $0.982)$ or age (LMM, $p=0.191)$, but it was significantly (LMM, $p=0.149)$ longer on the left 
$(0.71 \pm 0.16 \mathrm{~mm}$, range: $387-1107 \mu \mathrm{m}, \mathrm{N}=29)$ compared to right $(0.65 \pm 0.13 \mathrm{~mm}$, range: $365-858 \mu \mathrm{m}, \mathrm{N}=29$ ) (Fig. 8g). The area of the LDC was smaller (LMM, $p<0.001$ ) on the left $\left(4.1 \mathrm{e} 4 \pm 2.2 \mathrm{e} 4 \mu \mathrm{m}^{2}\right.$, range: $\left.1978-9.9 \mathrm{e} 4 \mu \mathrm{m}^{2}, \mathrm{~N}=29\right)$ compared to the right $(6.2 \mathrm{e} 4 \pm 3.0 \mathrm{e} 4$ $\mu \mathrm{m}^{2}$, range: $11867-1.1 \mathrm{e} 5 \mu \mathrm{m}^{2}, \mathrm{~N}=29$ ) hemi-syrinx and increased over development (LMM, $p=0.048$; Fig. 8h). Lastly, we approximated overall growth of the syrinx as the distance between both ends of the B4 cartilage in the bronchus, and found no significant change for side (LMM, $p=0.14)$, sex (LMM, $p=0.17)$, or age (LMM, $p=0.8)$ and was $1.85 \pm 0.23 \mathrm{~mm}$ (range: $1280-2196 \mu \mathrm{m}, \mathrm{N}=29$; Fig. 8i).

\section{Discussion}

As songbirds learn to sing, both their song system and vocal organ are undergoing postnatal changes that lead to dramatic changes in vocal behavior. Here we show that the acoustic output of the sound generators within the zebra finch syrinx does not change considerably over vocal development. This strongly suggests that the observed acoustic changes during vocal development are caused by changes in the motor control pathway, from song system circuitry to muscle force, and not by changes in the avian analog of the vocal folds. In other words, the size and properties of the instrument are not changing, but its player 413 is.

We show that both sides of the syrinx, or hemi-syrinxes, produce sound in a welldefined consistent pressure control space. The pressure space is bound by phonation threshold pressures (PTP) for $p_{\mathrm{b}}, p_{\text {icas }}$ and $p_{\mathrm{t}}$, which are the same for both sexes and sides. The $\mathrm{PTP}_{\mathrm{b}}$ values in adults of $1.01 \pm 0.28 \mathrm{kPa}$ reported here are consistent with earlier reported $\mathrm{PTP}_{\mathrm{b}}$ values of $1.2 \mathrm{kPa}$ in situ ${ }^{45}$ and in $v i v o^{31}$. The possibility to control the two respiratory pressures ( $p_{\mathrm{b}}$ and $p_{\text {icas }}$ ) independently is very different from laryngeal systems where no air sacs directly apply force on the vocal folds. To what extent birds can actively and independently control the magnitude of $p_{\mathrm{t}}$ in vivo during song remains unknown. Certainly, positive pressurization of $p_{\text {icas }}$ is an essential condition to achieve syringeal vibration in all investigated species in vivo, (e.g., zebra finches ${ }^{29}$ and in vitro ${ }^{15,46,47}$, and dynamic $p_{\mathrm{t}}$ changes up to $1 \mathrm{kPa}$ occur during vocalizations in ringdoves ${ }^{34,48-50}$.

Our data show that source level and fundamental frequency are modulated by respiratory pressures. Source level was driven by bronchial pressure, consistent with laryngeal 
with the idea that $p_{\mathrm{t}}$ acts as a force on the MVM that increases tension ${ }^{51,52}$, which has also been observed in collapsible tubes ${ }^{54}$. Interestingly, especially close to the phonation onset $f_{\mathrm{o}}$ modulation is steep $(200 \mathrm{~Hz} / \mathrm{kPa})$ and a dynamic $p_{\mathrm{t}}$ difference of $1 \mathrm{kPa}$ could in zebra finches lead to $f_{\mathrm{o}}$ modulation of comparable magnitude to full stimulation of the ventral syringeal muscle $^{15}$. In contrast, Wiener Entropy (WE) was not modulated systematically in the pressure space. However, over the course of song learning WE has been shown to change over multiple time scales, from within a day to weeks and months $s^{2,3,55}$ and increased entropy variance is linked to better learning success ${ }^{3,55}$. These data suggest that WE is under control of the motor systems of (i) the syrinx, by modulating collision force and thereby spectral slope of the sound source ${ }^{56}$, and (ii) the upper vocal tract, by changing resonance properties and thereby frequency content of the radiated sound ${ }^{57,58}$.

Mechanical efficiency may have been an important selecting factor during the evolution of the syrinx as a vocal organ ${ }^{59}$ and our data confirms that the mechanical efficiency of voiced sound production is indeed high in the avian syrinx compared to the mammalian larynx. Our data shows that about $0.05 \%(-33 \mathrm{~dB})$ of the flow energy is converted into sound, while in mammals, laryngeal ME is only about $1.10^{-3}$ to $0.01 \%(-50$ to $-40 \mathrm{~dB})$ in tigers (Titze et al., $2010)$ and $3.10^{-5}$ to $1.10^{-3} \%(-65$ to $-50 \mathrm{~dB})$ in marmosets $\left.{ }^{6}\right)$. ME in the rooster has been reported to be as high as $1.6 \%$ in vivo ${ }^{61}$. The ME of the zebra finch in vivo is likely to be higher than we measured in vitro, because our preparation does not include a vocal tract. The reported SL of the zebra finch is about $70-80 \mathrm{~dB}$ re $20 \mu \mathrm{Pa} @ 1 \mathrm{~m}^{62}$, while the SL of our isolated syrinx was 20-30 dB SPL lower. A conservative estimate of $10 \mathrm{~dB}$ SL increase (i.e. RMS is 3 times higher) while maintaining the same aerodynamic power, results in a 10-fold increase in radiated acoustic power and a ME of $0.5 \%(-23 \mathrm{~dB})$. This is already comparable to the very high efficiency reported by Brackenbury ${ }^{61}$. Furthermore, we observed slight differences of ME over development, but these effects were not as pronounced as the changes observed in marmosets, where the adult larynx produces louder and more efficient vocalisations than the infant larynx ${ }^{6}$. Thus, the ME of the zebra finch syrinx is very high already at $25 \mathrm{DPH}$ and remains unaffected by vocal development.

Our data shows that acoustic output of the syrinx is modulated smoothly within the pressure boundaries: both SL and $f_{\mathrm{o}}$ increased continuously with bronchial and air sac pressures. Thus when driven by physiologically relevant pressures, this nonlinear dynamic system exhibits only one bifurcation from steady (no vibration and no sound) to flow-induced self-sustained vibration, without additional bifurcations, such as period doublings or jumps to deterministic chaos ${ }^{45,63-66}$. Earlier work already showed that in a subset of the pressure control 
space in situ, additional bifurcations did not occur ${ }^{45}$. Moreover, the supposed bifurcations during song in vivo, e.g. frequency jumps, were shown to not be actual bifurcations ${ }^{45}$, but more likely millisecond scale modulation driven by superfast syringeal muscle ${ }^{67}$. Here we also show that in the independently controlled and densely sampled pressure control space of the zebra finch syrinx in vitro, additional bifurcations do not occur. Thus, driven by physiologically relevant pressures, the acoustic output of the syrinx is continuous, which simplifies sensorymotor control ${ }^{45}$.

The stable acoustic output of the sound generators over development suggests that its mechanical properties are not changing ${ }^{22,23}$ and acoustic output ${ }^{41,68,69}$ are common in songbirds. In all investigated species to date, except for the Bengalese finch ${ }^{15,69}$, the left hemi-syrinx produces lower frequencies.

The $f_{\mathrm{o}}$ of sound is determined by positioning of and driving pressures on the vocal folds, as well as their resonance properties ${ }^{20}$. Small changes in material properties can drive changes in vocalizations over development in marmosets ${ }^{6}$. Because we show that minimum frequency does not significantly change over development in vitro and in vivo, our data strongly suggest that the effective resonance properties of the syringeal sound generators when driven by physiological realistic pressures do not change over vocal development. Next to resonance properties, the change in MVM stiffness as response to shortening is also likely changing very little over development. Although we didn't measure directly how syringeal muscle force modulates MVM resonance properties over development, the $f_{\mathrm{o}}-p_{\mathrm{t}}$ relationship (S1) can be seen as a proxy of the effect of MVM lengthening by e.g. VS contraction, as $p_{\mathrm{t}}$ exerts a force on the MVM that causes changes in $\operatorname{strain}^{32}$. Taken together, the MVM vibration frequencies and its response to external force do not change, which strongly suggest that its material properties also do not change over development.

We propose that syringeal sound production on the one hand, and its control on the other, are shaped differentially by genetic and environmental factors. First, we propose that the development and maintenance of the sound generators is predominantly under genetic control. Second, we propose that the syringeal muscles and skeletal properties are heavily influenced by use, which can ultimately lead to a sexually dimorph syrinx.

Our data suggest that MVM mechanical properties are set and maintained by genetic factors. First, a salient feature in our dataset is that the adult left hemi-syrinx produces a lower minimal $f_{\mathrm{o}}$ compared to the right in both sexes, corroborating earlier findings ${ }^{20}$. In most

494 songbirds both hemi-syrinxes contribute to the vocal repertoire ${ }^{70,71}$ and left-right differences in 495 labial morphology $y^{22,23}$ and acoustic output ${ }^{41,68,69}$ are common in songbirds. In all investigated 
496 species to date, except for the Bengalese finch ${ }^{15,69}$, the left hemi-syrinx produces lower 497 frequencies. Here we show for the first time that differences between left and right sound 498 generators, size and acoustic output, are already established at 25 DPH. Second, we show that 499 neither the morphology, nor the acoustic output of the bilateral sound generators changes over 500 development. Thus, the MVM properties have matured already at $25 \mathrm{DPH}$. This latter feature 501 makes the songbird system a wonderful model system to study vocal development compared 502 to mammalian systems where larynx maturation strongly contributes to vocal output ${ }^{6,25-27}$.

503 Third, MVM properties remain constant even though they are colliding billions of times over 504 their lifetime and there must be a large variability in use between individuals and sexes. In 505 human vocal folds, strong collisions can lead to several types of lesions that severely affect 506 vocal output ${ }^{72}$. Thus, ultrastructural repair of vibratory tissues must lead to maintenance of 507 their properties, but what cellular and molecular mechanisms underlie this maintenance in birds 508 remains unknown. Taken together, these observations support the ideas that the sound 509 generators of the syrinx are matured at the onset of vocal learning, their composition remains 510 stable and is species specific, which suggests that their composition and dynamical behavior is 511 set by genetic factors and not affected by use. The zebra finch syrinx is thus a stable instrument 512 which's postnatal development does not add further complexity to song learning

513 In stark contrast, syringeal muscles are changing functionally over postnatal 514 development during song learning. Until 25 DPH the syrinx of male and female zebra finches 515 is not clearly distinguishable. However, after $25 \mathrm{DPH}$, the syringeal muscles start to exhibit 516 sexually dimorphic features, such as increased muscle mass ${ }^{11}$ and speed in males ${ }^{12}$, which leads 517 to a different action potential to force transform ${ }^{14}$. Furthermore, muscle force exerted on bones 518 is known to redirect bone deposition and thus can lead to significant bone remodelling ${ }^{73}$. Taken 519 together, we propose that in songbirds syringeal muscle activity and resulting forces acting on 520 the syrinx are crucially important drivers to the sexual dimorphism of bones and cartilages of 521 the syringeal skeleton. This implies that most anatomical changes are caused by muscle use 522 and training driven by the sexually dimorphic songbird brain (i.e., song system). As such the 523 instrument, i.e. the vocal folds, are not changing, but the player is. 


\section{References}

525 1. Takahashi, D. Y. et al. The developmental dynamics of marmoset monkey vocal 526 production. Science. 349, 734-738 (2015).

527 2. Tchernichovski, O., Mitra, P. P., Lints, T. \& Nottebohm, F. Dynamics of the vocal 528 imitation process: How a zebra finch learns its song. Science. 291, 2564-2569 (2001).

529 3. Kollmorgen, S., Hahnloser, R. H. R. \& Mante, V. Nearest neighbours reveal fast and 530 slow components of motor learning. Nature 577, 526-530 (2020).

531 4. Goldstein, M. H., King, A. P. \& West, M. J. Social interaction shapes babbling: Testing parallels between birdsong and speech. Proc. Natl. Acad. Sci. U. S. A. 100, 8030-8035 (2003).

534 5. Oller, D. K. et al. Functional flexibility of infant vocalization and the emergence of language. Proc. Natl. Acad. Sci. U. S. A. 110, 6318-6323 (2013).

6. Zhang, Y. S., Takahashi, D. Y., Liao, D. A., Ghazanfar, A. A. \& Elemans, C. P. H. Vocal state change through laryngeal development. Nat. Commun. 10, 1-12 (2019).

538 7. Fee, M. S. \& Scharff, C. The songbird as a model for the generation and learning of complex sequential behaviors. ILAR J. 51, 352-377 (2010).

540 8. Brainard, M. S. \& Doupe, A. J. Translating birdsong: Songbirds as a model for basic and applied medical research. Annu. Rev. Neurosci. 36, 489-517 (2013).

9. Liu, W. C., Wada, K. \& Nottebohm, F. Variable food begging calls are harbingers of vocal learning. PLoS One 4, e5929 (2009).

10. Darshan, R., Wood, W. E., Peters, S., Leblois, A. \& Hansel, D. A canonical neural mechanism for behavioral variability. Nat. Commun. 8, 15415 (2017).

11. Godsave, S. F., Lohmann, R., Vloet, R. P. M. \& Gahr, M. Androgen receptors in the embryonic zebra finch hindbrain suggest a function for maternal androgens in perihatching survival. J. Comp. Neurol. 453, 57-70 (2002).

12. Mead, A. F. et al. Fundamental constraints in synchronous muscle limit superfast motor control in vertebrates. Elife 6, e29425 (2017).

13. Adam, I. \& Elemans, C. P. H. Sensory and Motor Systems Vocal Motor Performance in Birdsong Requires Brain-Body Interaction. eNeuro 6, (2019).

14. Adam, I. \& Elemans, C. P. H. Increasing muscle speed drives changes in the neuromuscular transform of motor commands during postnatal development in songbirds. J. Neurosci. 40, 6722-6731 (2020).

15. Elemans, C. P. H. et al. Universal mechanisms of sound production and control in birds and mammals. Nat. Commun. 6, 1-13 (2015). 
16. Jiang, W. et al. High-fidelity continuum modeling predicts avian voiced sound production. Proc. Natl. Acad. Sci. U. S. A. 117, 4718-4723 (2020).

17. Goller, F. \& Larsen, O. N. A new mechanism of sound generation in songbirds. Proc. Natl. Acad. Sci. 94, 14787-14791 (1997).

18. Mindlin, G. B. \& Laje, R. The Physics of Birdsong. Springer Science \& Business Media (2006).

19. Titze, I. R. Principles of voice production. (National Center for Voice and Speech, 2000).

20. Fee, M. S. Measurement of the linear and nonlinear mechanical properties of the oscine syrinx: Implications for function. J. Comp. Physiol. A Neuroethol. Sensory, Neural, Behav. Physiol. 188, 829-839 (2002).

21. Düring, D. N. et al. The songbird syrinx morphome: A three-dimensional, highresolution, interactive morphological map of the zebra finch vocal organ. BMC Biol. 11, 1 (2013).

22. Riede, T. \& Goller, F. Functional morphology of the sound-generating labia in the syrinx of two songbird species. J. Anat. 216, 23-36 (2010).

23. Riede, T. \& Goller, F. Morphological basis for the evolution of acoustic diversity in oscine songbirds. Proc. R. Soc. B Biol. Sci. 281, 20132306-20132306 (2014).

24. S Švec, J. G., Horáček, J., Šram, F. \& Veselý, J. Resonance properties of the vocal folds: In vivo laryngoscopic investigation of the externally excited laryngeal vibrations. $J$. Acoust. Soc. Am. 108, 1397-1407 (2000).

25. Sato, K., Hirano, M. \& Nakashima, T. Age-related changes of collagenous fibers in the human vocal fold mucosa. Ann. Otol. Rhinol. Laryngol. 111, 15-20 (2002).

26. Hammond, T. H., Gray, S. D., Butler, J., Zhou, R. \& Hammond, E. Age- and genderrelated elastin distribution changes in human vocal folds. Otolaryngol. - Head Neck Surg. 119, 314-322 (1998).

27. Hammond, T. H. \& Gray, S. D. A study of age- and gender-related elastin distribution changes in human vocal folds. Otolaryngol. - Head Neck Surg. 117, 100 (1997).

28. Gaunt, A. S., Stein, R. C. \& Gaunt, S. L. L. L. Pressure and air flow during distress calls of the starling, Sturnus vulgaris (Aves;Passeriformes). J. Exp. Zool. 183, 241-261 (1973).

29. Amador, A. \& Margoliash, D. A Mechanism for Frequency Modulation in Songbirds Shared with Humans. J. Neurosci. 33, 11136-11144 (2013).

30. Setterwall, C. G. Syrinx hos polymyoda passeres. Gleerupska Univ. 1-105 (1901). 
31. Riede, T.\& Goller, F. Peripheral mechanisms for vocal production in birds - differences and similarities to human speech and singing. Brain Lang. 115, 69-80 (2010).

32. Düring, D. N., Knörlein, B. J. \& Elemans, C. P. H. H. In situ vocal fold properties and pitch prediction by dynamic actuation of the songbird syrinx. Sci. Rep. 7, 11296 (2017).

33. Srivastava, K. H., Elemans, C. P. H. \& Sober, S. J. Multifunctional and ContextDependent Control of Vocal Acoustics by Individual Muscles. J. Neurosci. 35, $14183-$ 14194 (2015).

34. Elemans, C. P. H. et al. Syringeal muscles fit the trill in ring doves (Streptopelia risoria L.). J. Exp. Biol. 209, 965-977 (2006).

35. de Cheveigné, A. \& Kawahara, H. YIN, a fundamental frequency estimator for speech and music. J. Acoust. Soc. Am. 111, 1917-1930 (2002).

36. The Mathworks Inc. MATLAB - MathWorks. www.mathworks.com/products/matlab (2016).

37. R Development Core Team. A Language and Environment for Statistical Computing. $R$ Found. Stat. Comput. (2018).

38. Schindelin, J. et al. Fiji: An open-source platform for biological-image analysis. Nat. Methods 9, 676-682 (2012).

39. Tchernichovski, O., Nottebohm, F., Ho, C. E., Pesaran, B. \& Mitra, P. P. A procedure for an automated measurement of song similarity. Anim. Behav. (2000).

40. Roy, A. \& Mooney, R. Auditory plasticity in a basal ganglia-forebrain pathway during decrystallization of adult birdsong. J. Neurosci. 27, 6374-6387 (2007).

41. Williams, H., Crane, L. A., Hale, T. K., Esposito, M. A. \& Nottebohm, F. Right-side dominance for song control in the zebra finch. J. Neurobiol. 23, 1006-1020 (1992).

42. Riede, T., Fisher, J. H. \& Goller, F. Sexual dimorphism of the zebra finch syrinx indicates adaptation for high fundamental frequencies in males. PLoS One 5, e11368 (2010).

43. Kuznetsova, A., Brockhoff, P. B. \& Christensen, R. H. B. lmerTest Package: Tests in Linear Mixed Effects Models . J. Stat. Softw. (2017).

44. Bates, D., Maechler, M., Bolker, B. \& Walker, S. lme4: linear mixed-effects models using S4 classes. R package version 1.1-6. $R$ (2014).

45. Elemans, C. P. H., Laje, R., Mindlin, G. B. \& Goller, F. Smooth operator: Avoidance of subharmonic bifurcations through mechanical mechanisms simplifies song motor control in adult zebra finches. J. Neurosci. 30, 13246-13253 (2010).

46. Rüppell, W. Physiologie und Akustik der Vogelstimme. J. für Ornithol. 81, 433-542 
(1933).

47. Abs, M. On the Bioacoustics of the Breaking of the Birds Voice. Zool. JAHRBUCHERABTEILUNG FUR Allg. Zool. UND Physiol. DER TIERE 84, 289-382 (1980).

48. Gaunt, A., Gaunt, S. L. \& Casey, R. Syringeal Mechanics Reassessed: Evidence from Streptopelia. Auk 99, 474-494 (1982).

49. Beckers, G. J. L., Nelson, B. S. \& Suthers, R. A. Vocal-tract filtering by lingual articulation in a parrot. Curr. Biol. 14, 1592-1597 (2004).

50. Elemans, C. P. H., Zaccarelli, R. \& Herzel, H. Biomechanics and control of vocalization in a non-songbird. J. R. Soc. Interface 5, 691-703 (2008).

51. Elemans, C. P. H. H., Muller, M., Larsen, O. N. \& Van Leeuwen, J. L. Amplitude and frequency modulation control of sound production in a mechanical model of the avian syrinx. J. Exp. Biol. 212, 1212-1224 (2009).

52. Elemans, C. P. H., Heeck, K. \& Muller, M. Spectrogram analysis of animal sound production. Bioacoustics 18, 183-212 (2008).

53. Bertramt, C. D., Pedley, T. J. J., Bertram, C. D. D. \& Pedley, T. J. J. A mathematical model of unsteady collapsible tube behaviour. J. Biomech. 15, 39-50 (1982).

54. Bertram, C. D. Flow phenomena in floppy tubes. Contemp. Phys. 45, 45-60 (2004).

55. Derégnaucourt, S., Mitra, P. P., Fehér, O., Pytte, C. \& Tchernichovski, O. How sleep affects the developmental learning of bird song. Nature 433, 710-716 (2005).

56. Hunter, E. J., Titze, I. R. \& Alipour, F. A three-dimensional model of vocal fold abduction/adduction. J. Acoust. Soc. Am. 115, 1747-1759 (2004).

57. Ohms, V. R., Beckers, G. J. L., ten Cate, C. \& Suthers, R. A. Vocal tract articulation revisited: the case of the monk parakeet. J. Exp. Biol. 215, 85-92 (2012).

58. Riede, T., Suthers, R. A., Fletcher, N. H. \& Blevins, W. E. Songbirds tune their vocal tract to the fundamental frequency of their song. Proc. Natl. Acad. Sci. 103, 5543-5548 (2006).

59. Riede, T., Thomson, S. L., Titze, I. R. \& Goller, F. The evolution of the syrinx: An acoustic theory. PLoS Biol. 17, 1-22 (2019).

60. Ingo R. Titze, W. Tecumseh Fitch, Eric J. Hunter, Fariborz Alipour, Douglas Montequin, Douglas L. Armstrong, JoAnn McGee, E. J. W. Vocal power and pressureflow relationships in excised tiger larynges. J. Exp. Biol. 213, 3866-3873 (2010).

61. Brackenbury, J. H. Physiological energetics of cock-crow. Nature 270, 433-435 (1977).

62. Brumm, H. \& Ritschard, M. Song amplitude affects territorial aggression of male receivers in chaffinches. Behav. Ecol. 22, 310-316 (2011). 
660

661

662

663

664

665

666

667

668

669

670

671

672

673

674

675

676

677

678

679

680

681

682

683

684

63. Wilden, I., Tembrock, G., Herzel, H. \& Peters, G. Subharmonics, biphonation, and deterministic chaos in mammal vocalization. Bioacoustics 9, 171-196 (1998).

64. Laje, R., Gardner, T. J. \& Mindlin, G. B. Neuromuscular control of vocalizations in birdsong: A model. Phys. Rev. E - Stat. Physics, Plasmas, Fluids, Relat. Interdiscip. Top. 65, 051921 (2002).

65. Gardner, T., Cecchi, G., Magnasco, M., Laje, R. \& Mindlin, G. B. Simple motor gestures for birdsongs. Phys. Rev. Lett. 87, 208101 (2001).

66. Amador, A., Perl, Y. S., Mindlin, G. B. \& Margoliash, D. Elemental gesture dynamics are encoded by song premotor cortical neurons. Nature 495, 59-64 (2013).

67. Elemans, C. P. H., Mead, A. F., Rome, L. C. \& Goller, F. Superfast vocal muscles control song production in songbirds. PLoS One 3, 6-11 (2008).

68. Nottebohm, F. \& Nottebohm, M. E. Left hypoglossal dominance in the control of canary and white-crowned sparrow song. J. Comp. Physiol. 108, 171-192 (1976).

69. Secora, K. R. et al. Syringeal specialization of frequency control during song production in the bengalese finch (lonchura striata domestica). PLoS One 7, e34135 (2012).

70. Suthers, R. A. How birds sing and why it matters. in Nature's Music: The Science of Birdsong 272-295 (2004).

71. Suthers, R. A. \& Zollinger, S. A. From brain to song: the vocal organ and vocal tract. Neuorscience of Birdsong 78-98 (2008).

72. Titze, I. R. \& Hunter, E. J. Comparison of vocal vibration-dose measures for potentialdamage risk criteria. J. Speech, Lang. Hear. Res. 58, 1425-1439 (2015).

73. Robling, A. G., Castillo, A. B. \& Turner, C. H. Biomechanical and molecular regulation of bone remodeling. Annu. Rev. Biomed. Eng. 8, 455-498 (2006). 


\section{Acknowledgments}

686 The authors wish to thank Torben Christensen and Sonja Jakobsen for technical support, Emil

687 B. Hansen for help with breeding, and John Jackson for assistance with statistical analysis.

688

\section{Author Contributions}

690 A.M., I.A. \& C.E. conceived the study. A.M., I.A. \& C.E. developed technical methods. I.A. 691 \& C.E. provided reagents and materials. A.M. \& P.L. performed in vitro experiments and 692 collected all data. I.A., P.S. \& C.E. performed in vivo experiments and collected all data. A.M., 693 I.A. \& C.E. analysed the data. A.M. prepared all figures and tables. A.M., I.A. \& C.E. wrote 694 the manuscript. All authors read and approved the final version of the manuscript.

695

696 Additional Information: The authors declare that they have no competing interests.

697

\section{Funding}

699 This work was supported by the Danish Research Council (Grant DFF 5051-00195), the

700 Carlsberg Foundation (Grant CF17-0949) to I.A. and Novo Nordisk Foundation (Grant 701 NNF17OC0028928) to C.P.H.E

\section{Data Availability}

704 The datasets generated during and/or analysed during the current study are available from the corresponding author on reasonable request. 


\section{Figures and legends}

707 Figure 1
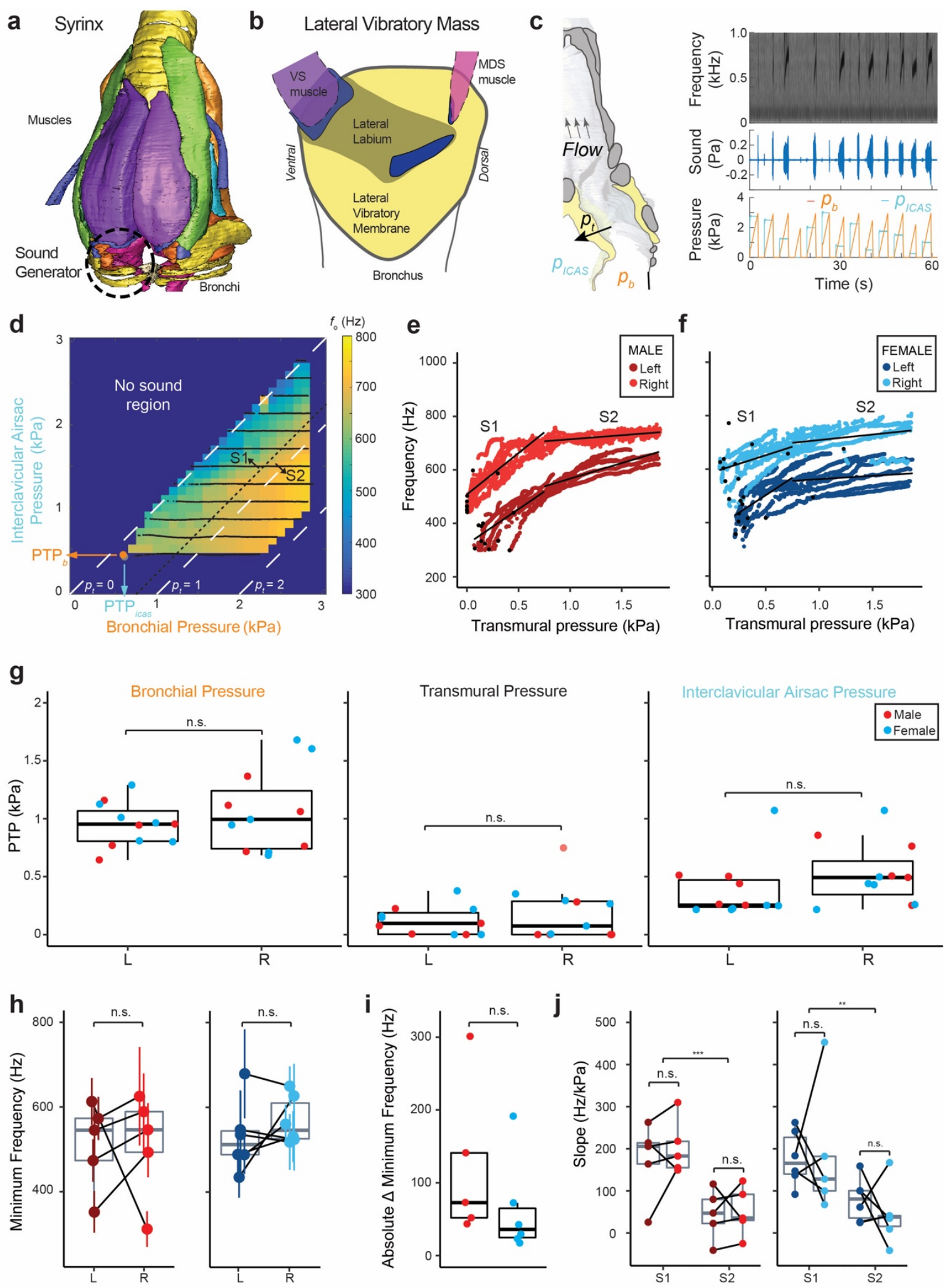

generators are indicated by a dashed circle. (b) Schematic view on the sound generator's lateral vibratory mass. (c) Schematic sagittal cross-section through the syrinx of the left bronchus, indicating the movement of pressures around and through the syrinx. Example raw data of sound production induced by bronchial and interclavicular air sac pressures (d) Example of fundamental frequencies produced in the pressure control space for the right hemi-syrinx of an adult male zebra finch (100 DPH). Phonation threshold pressures (PTP) are indicated for: PTP icas (grey dot), and PTP (red dot). Transmural pressure ( $p_{\mathrm{t}}$ is indicated by white dashed lines for $p_{\mathrm{t}}=0,1$ and $3 \mathrm{kPa}$. (ef) Frequency increases with $p_{\mathrm{t}}$ for both the left (dark red, dark blue) and right hemi-syrinx (light red, light blue) in males and (c) females, respectively. Black lines indicate linear regressions for region $\mathrm{S} 1\left(0<p_{\mathrm{t}}<0.75\right)$ and $\mathrm{S} 2\left(p_{\mathrm{t}}>0.75\right)$. The phonation threshold pressure (PTP) values for individual $p_{\text {icas }}$ ramps are indicated by black circles. (g) PTP for $p_{\mathrm{b}}, p_{\mathrm{t}}$, and $p_{\text {icas }}(\mathrm{kPa})$, for the left and right hemi-syrinx. (h) Minimum frequency produced by the right hemi-syrinx was higher than the left hemi-syrinx ( $\mathrm{p}=0.09$, see Table S1) for most individuals. (i) The absolute difference of minimal $f_{\mathrm{o}}$ was not significantly different between males and females. (j) Slopes for the left and right hemisyrinx did not differ significantly between sides but were significantly steeper in S1 than in S2. For statistics see Supplementary Table S1. *, $\mathrm{p}<0.05 ;{ }^{* *}, \mathrm{p}<0.01 ;{ }^{* * *}, \mathrm{p}<0.001$. 
Figure 2

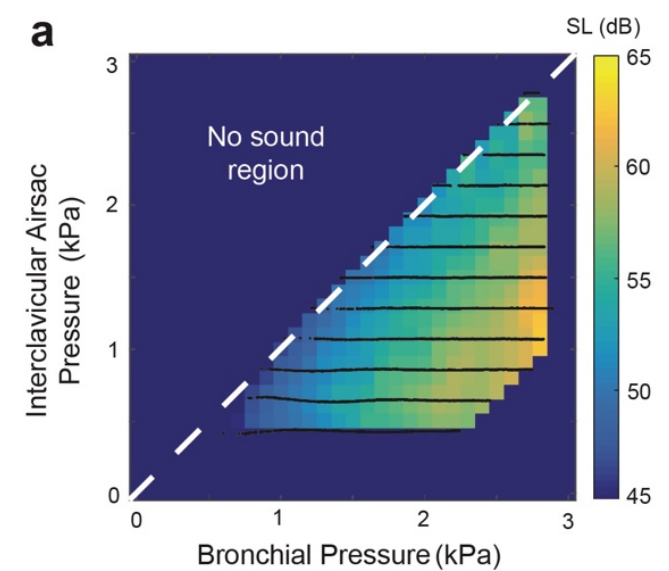

b

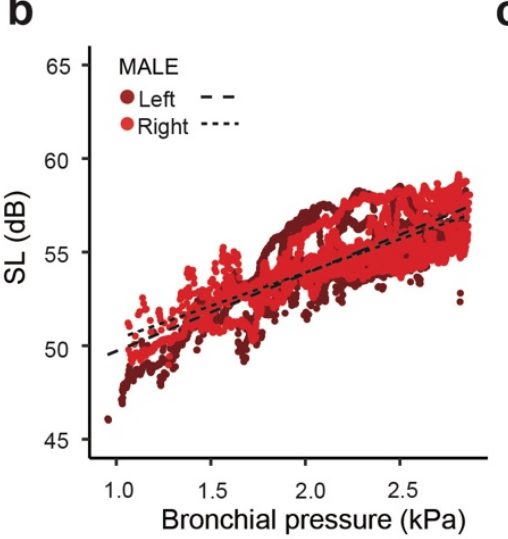

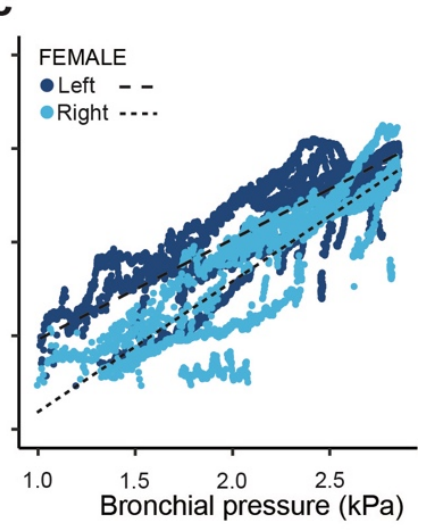
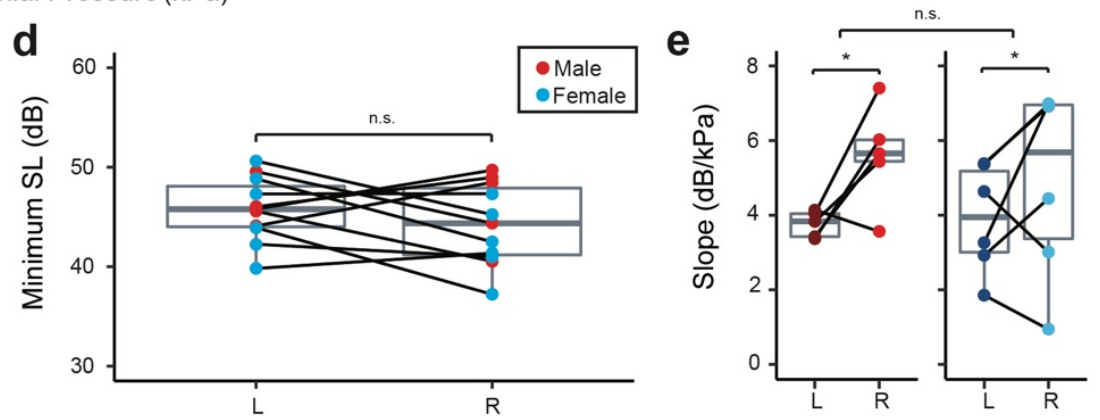

Figure 2. Source level increases with bronchial pressure in the adult zebra finch hemi-

syrinx. (a) Example of source level (SL) produced in the pressure control space for the left hemi-syrinx of an adult male zebra finch (100 DPH). Source level increases with $p_{b}$ for both the left (dark red, dark blue) and right hemi-syrinx (light red, light blue) in (b) males and (c) females, respectively. Black dashed lines indicate linear regressions (Left: long dash; Right: short dash). (d) Minimum SL does not differ significantly between the left and right hemisyrinx or between males and females. (e) The SL increase with bronchial pressure was significantly steeper for the right hemi-syrinx than the left hemi-syrinx. For statistics see Supplementary Table S1. *, $\mathrm{p}<0.05$. 
$740 \quad$ Figure 3

741

742

743

744

745

746 a

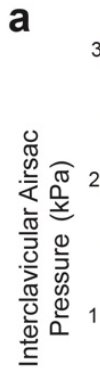

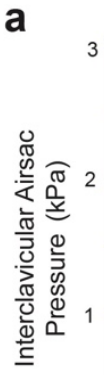

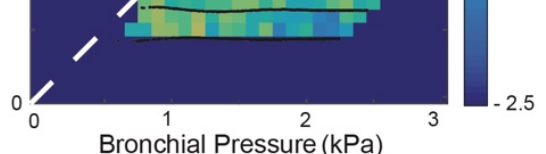

b

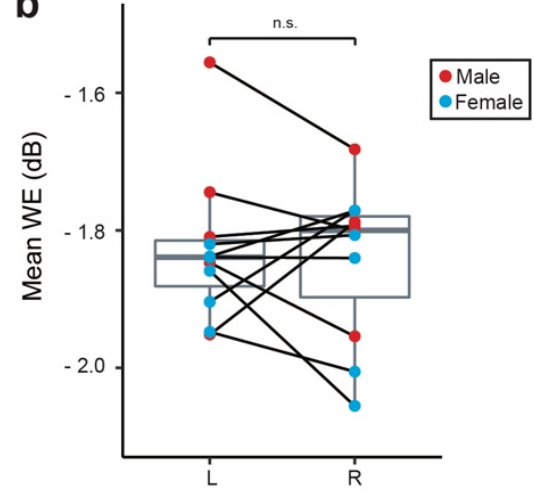

Figure 3. Wiener entropy is not affected by pressure in the adult zebra finch hemisyrinx. (a) Wiener entropy (WE) produced in the pressure control space for the left hemisyrinx of an adult male zebra finch (100 DPH). (b) Mean WE of the left and right hemisyrinx was not significantly different between male and female zebra finches or for left and right hemi-syrinxes. For statistics see Supplementary Table S1. 
$747 \quad$ Figure 4
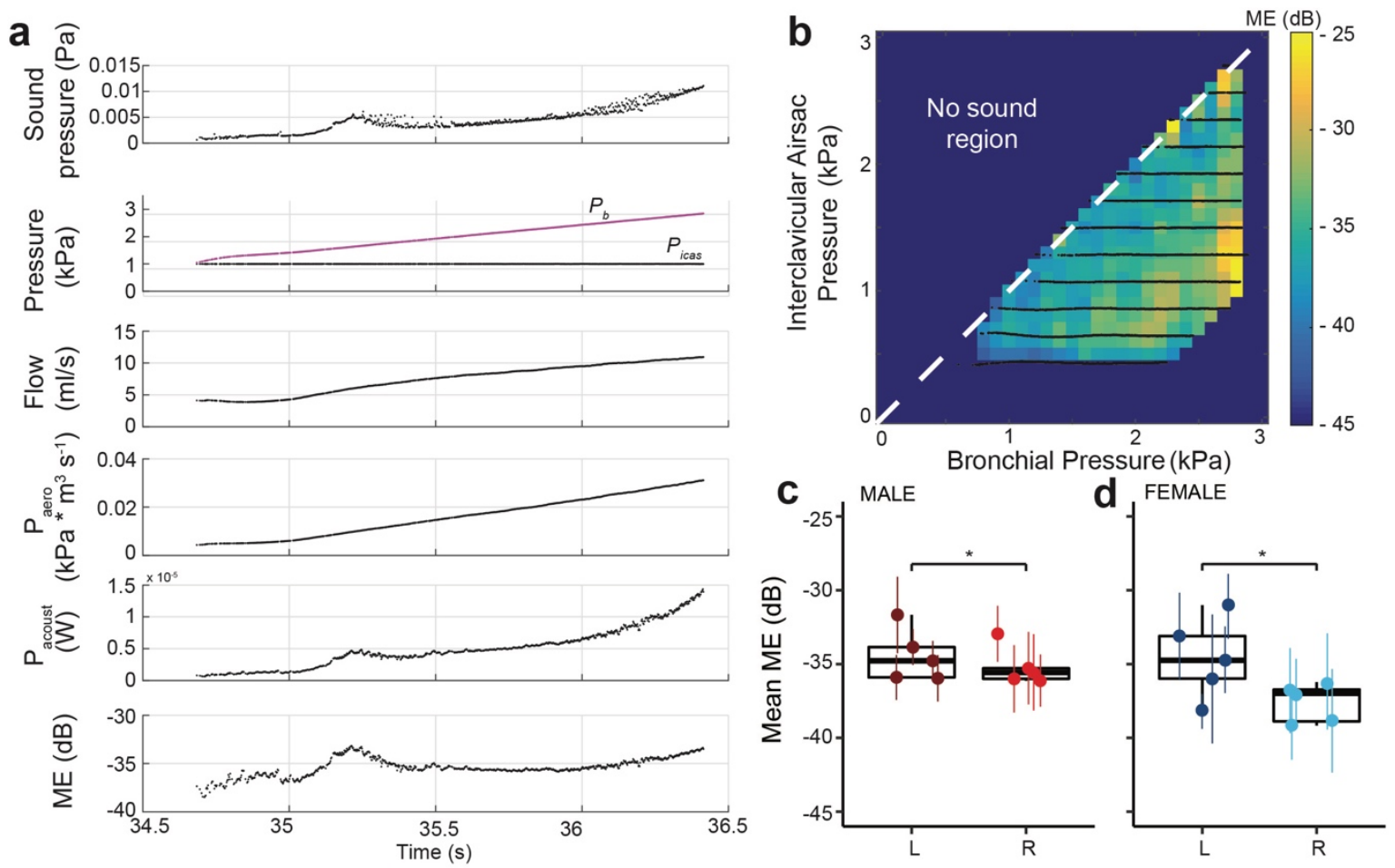

Figure 4. Mechanical efficiency is not affected by respiratory pressure, but lower on the right side of adult zebra finch. (a) Example of one $p_{\mathrm{b}}$-ramp (from top to bottom) received sound pressure $(\mathrm{Pa})$, bronchial and interclavicular air sac pressures $(\mathrm{kPa})$, acoustic and aerodynamic power $(\mathrm{W})$, and mechanical efficiency (ME) (dB). (b) Mechanical efficiency in the pressure control space for the left hemi-syrinx of an adult male zebra finch (100 DPH). (c, d) Mechanical efficiency was significantly higher for the left hemi-syrinx than the right hemi-syrinx in both sexes. For statistics see Supplementary Table S1. *, $\mathrm{p}<0.05$. 
Figure 5
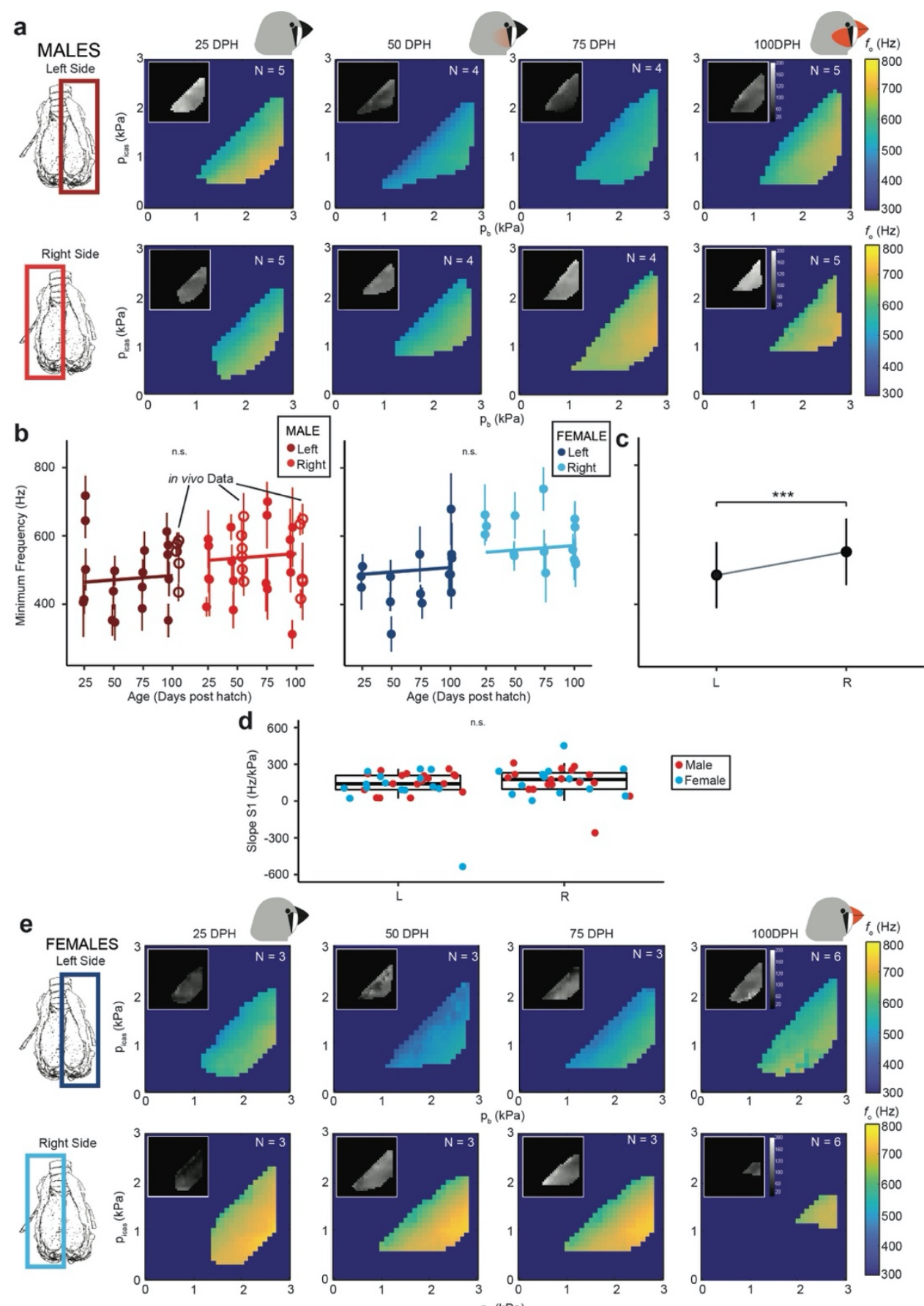

Figure 5. Minimal frequency does not change over zebra finch song development. (a)

Fundamental frequency in the pb picas pressure control space for the left and right hemi-syrinx in males over vocal development $f_{\mathrm{o}}$ values are averaged over all individuals within a group (insets S.D.). (b) Minimum $f_{\mathrm{o}}$ does not change with age in males and females. (c) Minimum frequency was significantly different between the left and right hemi-syrinx, regardless of age or sex. (d) Slope S1 for the relationship between $f_{\mathrm{o}}$ and $p_{\mathrm{t}}$ was not significantly different for side. (e) Pressure control spaces in vitro for the left and right hemi-syrinx in females. For statistics see Supplementary Table 
Figure 6
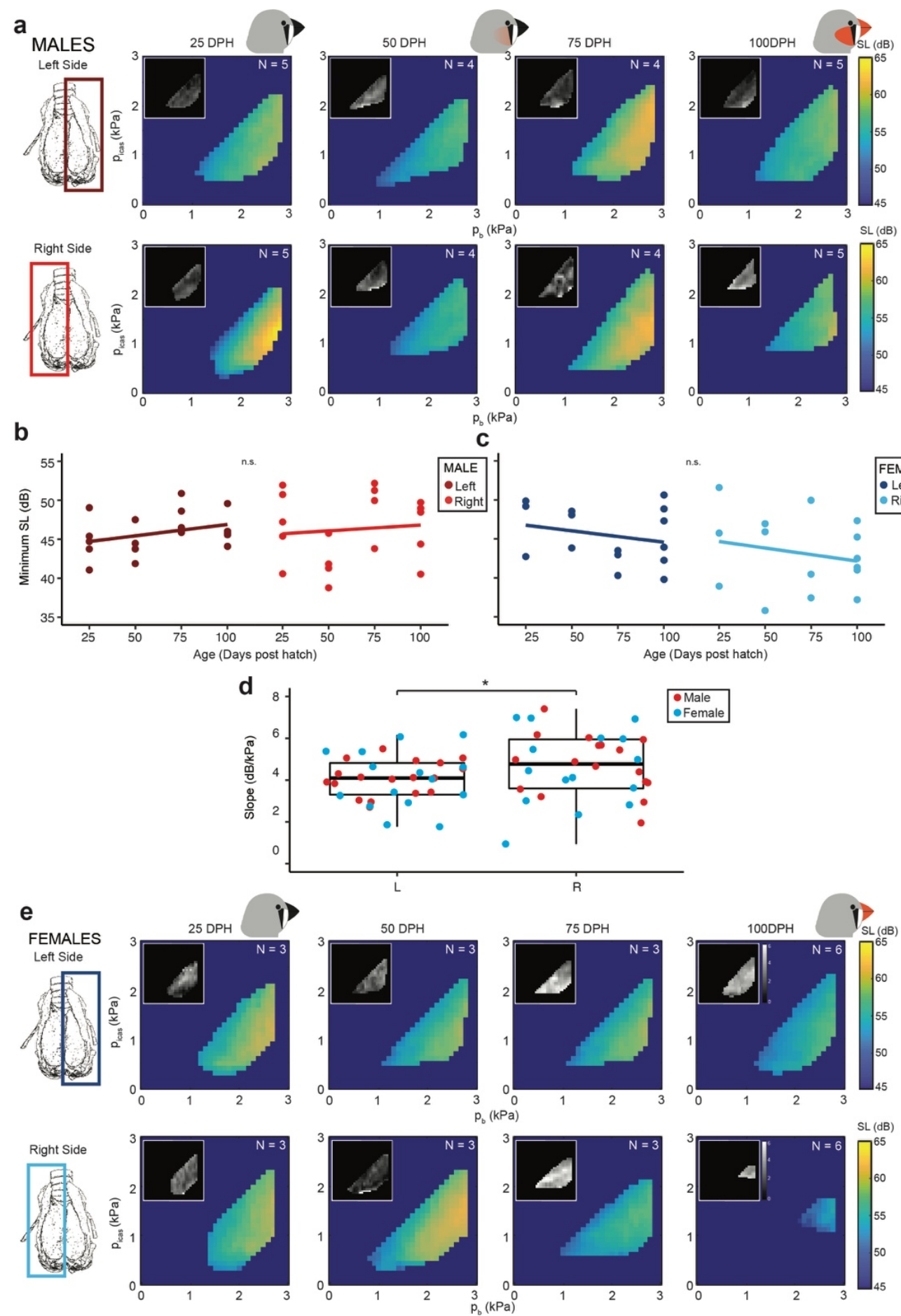

Figure 6. Minimum source level (SL) does not change over zebra finch song development. (a)

Mean SL pressure control spaces in vitro for the left and right hemi-syrinx in males (inset S.D.).

Minimum SL produced for (b) males and (c) females does not change over development, nor was it significantly different between sides. (d) Slope for the relationship between SL and $p_{\mathrm{b}}$ was significantly steeper on the right compared to the left hemi-syrinx. (e) Mean SL pressure control 
Figure 7
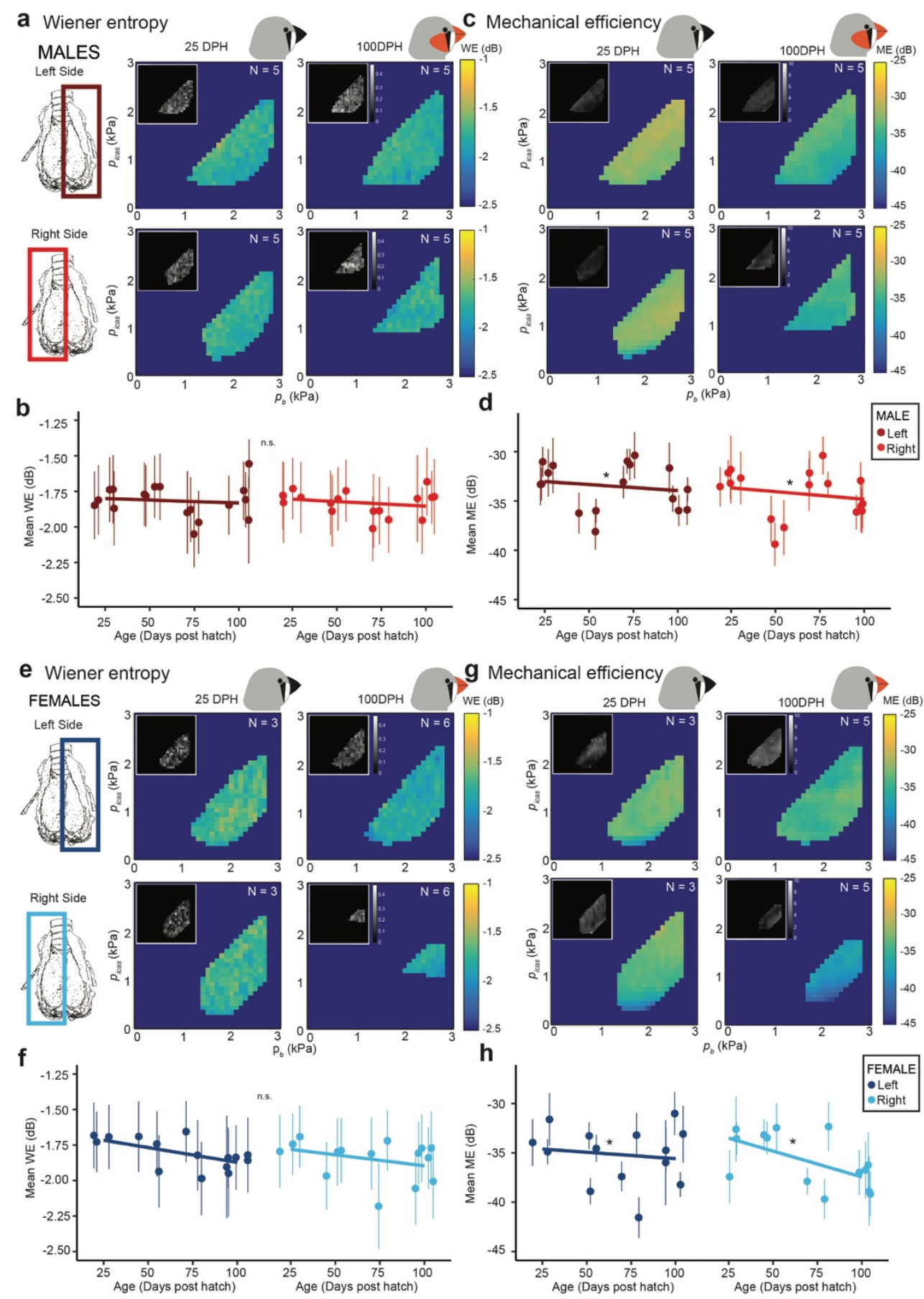

Figure 7. Wiener entropy and mechanical efficiency do not change over zebra finch song development. (a) Wiener entropy (WE) for the left and right hemi-syrinx in males age 25 and 100 DPH. (b) WE did not change for males over development. (c) Mechanical efficiency (ME) for the left and right hemi-syrinx in males age 25 and $100 \mathrm{DPH}$. (d) The mean ME produced for males significantly differed over development. (e) Wiener entropy (WE) for the left and right hemi-syrinx in females age 25 and 100 DPH. (f) In females, WE did not significantly change over development. (g) Mechanical efficiency (ME) for the left and right hemi-syrinx in females age 25 and $100 \mathrm{DPH}$. 
Figure 8

a

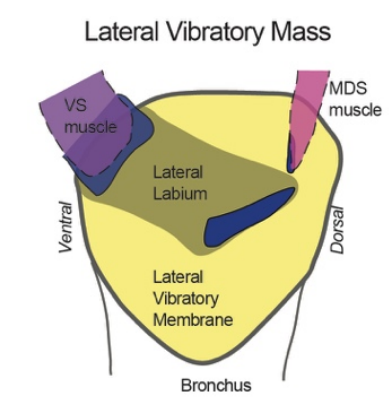

b

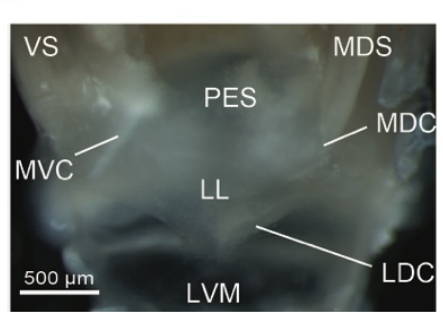

c

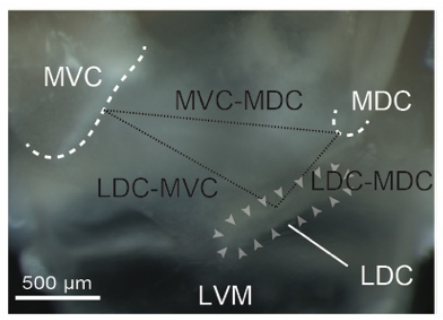

d MALES

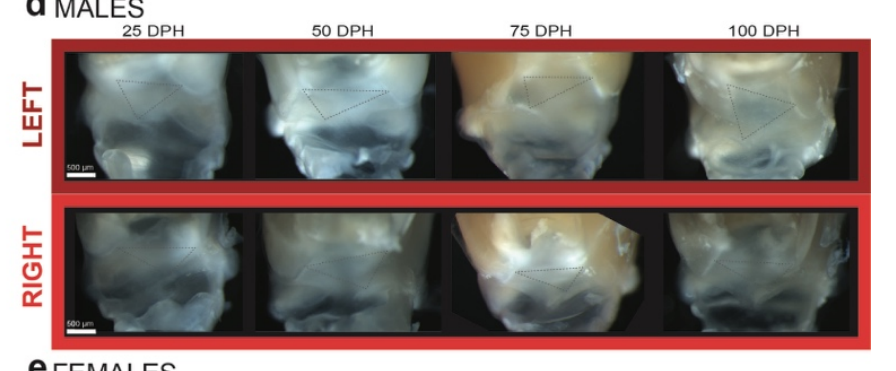

e FEMALES

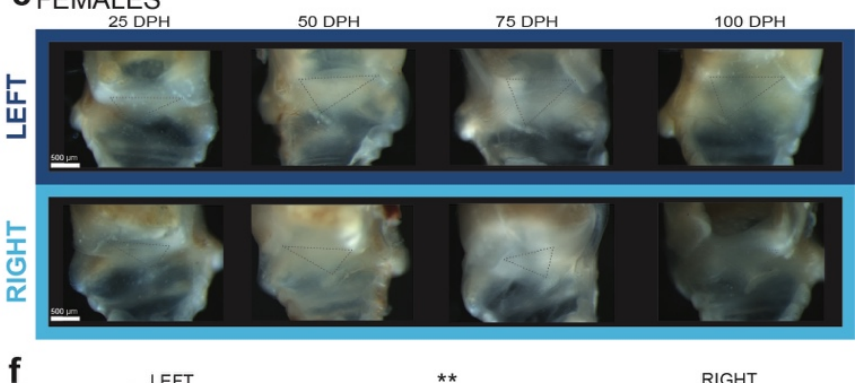

f
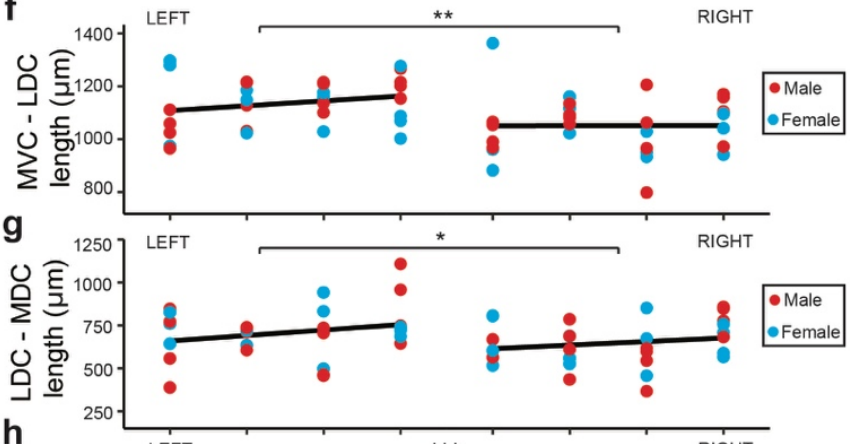

h
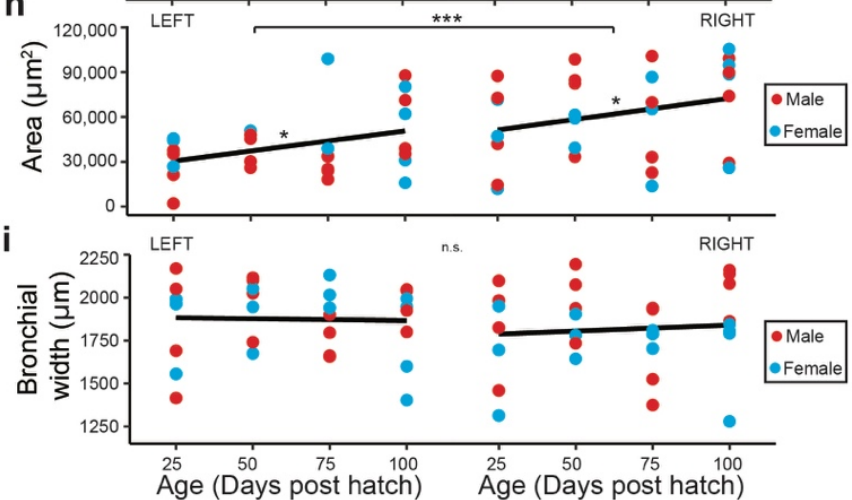

Schematic of lateral vibratory mass. (b) Physiological landmarks in the ML, the medio-ventral cartilage (MVC), the medio-dorsal cartilage (MDC) and the lateral dorsal cartilage (LDC) and (c) the distance between landmarks. (d,e) Example images of MTMs of left/right and male/female hemisyrinx. (f) MVC-LDC length was significantly different between sides, but not over development. (g) LDC-MDC length significantly differed between sides, but not over development. (h) LDC area for the four investigated age groups was significantly different and differed significantly between see Supplementary Table S3. *, $\mathrm{p}<0.05 ;{ }^{* *}, \mathrm{p}<0.01 ;{ }^{* * *}, \mathrm{p}<0.001$. 